\title{
The Research of Evaluation Metric of the Smart Growth Based on the Gray Correlation Analysis
}

\author{
Xiaoshuai $\mathrm{Wu}$ \\ School of North China Electric Power University, Baoding 071003, China; \\ 1337167317@qq.com
}

Keywords: smart growth; evaluation metric; Gray Correlation Analysis

\begin{abstract}
In recent years, many communities are implementing smart growth initiatives in an effort to consider long range, sustainable planning goals. However, there is not a suitable metric to measure the success of smart growth of a city. This paper first describes the connotation of the smart growth. According to the principles of the smart growth, we select six metrics to measure the success of a city. Then by correctly changing the value of each metric, we get two hypothetical cities (the best one and the worst one) and regard them as standard cities for further evaluation. Later, based on Gray Correlation Analysis and Improved Entropy Method, we define a metric named "Smart Growth Metric” (SGM).
\end{abstract}

\section{Introduction.}

"Smart growth is about helping every town and city become a more economically prosperous, socially equitable, and environmentally sustainable place to live." ${ }^{[1]}$ The ten principles for smart growth are ${ }^{[2]}$

\section{Mix land uses}

2 Take advantage of compact building design

3 Create a range of housing opportunities and choices

4 Create walkable neighborhoods

5 Foster distinctive, attractive communities with a strong sense of place

6 Preserve open space, farmland, natural beauty, and critical environmental areas

7 Strengthen and direct development towards existing communities

8 Provide a variety of transportation choices

9 Make development decisions predictable, fair, and cost effective

10 Encourage community and stakeholder collaboration in development decisions

While enormous changes have occurred in the world, then, as now, dealing with growth is a persistent theme. Many cities are implementing smart growth initiatives in an effort to consider long range, sustainable planning goals. Smart growth is about helping every town and city become a more economically prosperous, socially equitable, and environmentally sustainable place to live. In China, Qiang Ma and Xunchu Xu's article “Smart Growth” Strategy and Urban Spatial Expansion in China also involves the smart growth. ${ }^{[3]}$ 
Symbols and Definitions

Table 1 variable description

\begin{tabular}{cc}
\hline Abbreviation & Meaning \\
\hline SGM & Smart Growth Metric \\
GRP & Growth Rate of Population \\
EPI & Environmental Performance Index \\
PCDI & Per Capita Disposable Income \\
UR & Unemployment Rate \\
EC & Engels Coefficient \\
GC & Geordie Coefficient \\
\hline
\end{tabular}

The research of evaluation metric of the smart growth city

In this section, we use grey correlation analysis to evaluate. Then we use grey weighted related degree to define the SGM.

\subsection{Construct hypothetical cities}

In order to measure the success of smart growth of a city, we have constructed the worst city and the best city according to the actual situation. Specific data in Table 2.

Table 2 Specific data of the two hypothetical cities

\begin{tabular}{ccc}
\hline Metric & the worst city & the best city \\
\hline GC & 1 & 0 \\
EC & 1 & 0 \\
UR & 0.247 & 0 \\
PCDI & 100 & 100000 \\
GRP & 0.03833 & 0 \\
EPI & 0 & 100 \\
\hline
\end{tabular}

\subsection{Gray Correlation Analysis}

Grey correlation analysis of the steps are as follows:

- Determine the comparative object (evaluation object) and the reference number series (evaluation criteria). Assume the number of the evaluation object is $\boldsymbol{m}$, the number of the reference number series is $n$, the reference number series are $x_{0}=\left\{x_{0}(k) \mid \mathbf{k}=1,2, \cdots, \mathbf{n}\right\}$, the evaluation number series are $x_{i}=\left\{x_{i}(k) \mid k=1,2, \cdots n\right\}, i=1,2, \cdots m$.

- Determine the weight of each index corresponds to the value $\boldsymbol{w}=\left[\boldsymbol{w}_{1}, \cdots, \boldsymbol{w}_{n}\right]$. Among them, $\boldsymbol{w}_{\boldsymbol{k}}(\boldsymbol{k}=\mathbf{1}, \mathbf{2}, \cdots \boldsymbol{n})$ is the $\boldsymbol{k}$ th evaluation index weight.

- Calculate the grey correlation coefficient:

$$
\xi_{i}(k)=\frac{\min _{s} \min _{t}\left|x_{0}(t)-x_{s}(t)\right|+\rho \max _{s} \max _{t}\left|x_{0}(t)-x_{s}(t)\right|}{\left|x_{0}(k)-x_{i}(k)\right|+\rho \max _{s} \max _{t}\left|x_{o}(t)-x_{s}(t)\right|}
$$

is the correlation coefficient between the comparison number series $\boldsymbol{x}_{\boldsymbol{i}}$ and the reference number series $\boldsymbol{x}_{\mathbf{0}}$ on the $\boldsymbol{k}$ th index. $\boldsymbol{\rho} \in[\mathbf{0 , 1}]$ is resolution coefficient. Among them,

$$
\min _{s} \min _{t}\left|x_{0}(t)-x_{s}(t)\right|
$$

is two minimum difference;

$$
\max _{s} \max _{t}\left|x_{0}(t)-x_{s}(t)\right|
$$

is two maximum difference.

- In General, the larger resolution coefficient $\rho$ is, the larger resolution is; the smaller resolution 
coefficient $\rho$ is, the smaller resolution is.

- Calculate grey weighted related degree. Its formula is:

$$
\gamma_{i}=\sum_{k=1}^{n} \omega_{i} \xi_{i}(k)
$$

Among them, $\boldsymbol{r}_{\boldsymbol{i}}$ is the $\boldsymbol{i}$ th evaluation of grey weighted related degree to ideal object.

- Evaluation and analysis. Depend on the size of grey weighted related degree, sort the objects and establish the correlation of evaluation object. The larger correlation is, the better the results of its evaluation.

\subsection{Obtain the value of SGM}

According to the steps of Gray Correlation Analysis, we can get the matrix of related degree value by MATLAB programming. As follows:

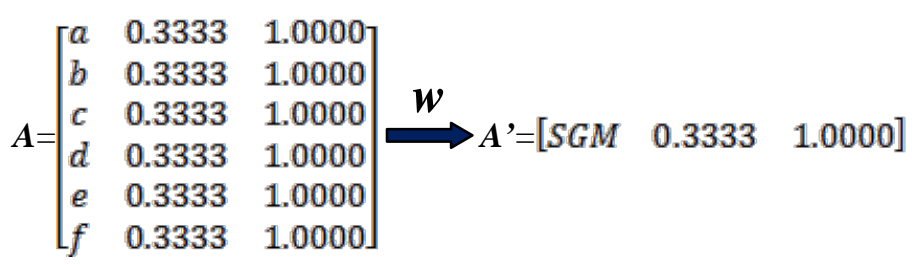

In the A matrix, the meaning of the first column is city's metrics (GC, EC, UR, PCDI, GRP and EPI) which have been standardized. The next following are the worst city's and the best city's.

In the A' matrix, by linking the metrics and weights, we get the grey weighted related degrees which reflect in turn a city, the worst city and the best city.

Thus, through the above work, we can obtain the value of SGM in the A' matrix. The greater the value of SGM is, the more successful the city's smart growth is.

\subsection{Evaluate Zouping city, China from 2009 to 2015}

According to the data ${ }^{[4]-[8]}$ from the network of Zouping government and Yale University, we follow the above steps to get the seven-year SGM and draw with Excel.

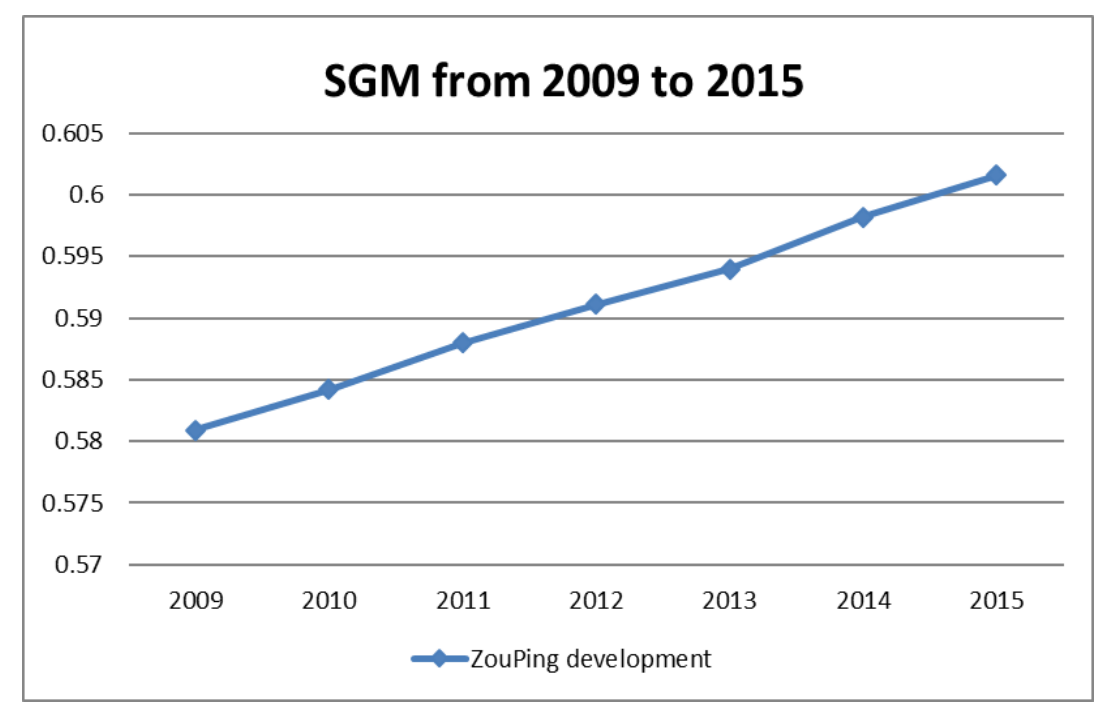

Figure 1 SGM from 2009 to 2015 
As can be seen from Figure 1, the SGM of Zouping city is increasing gradually. It means that the city becomes more and more sustainable. According to the report delivered by government, our result is in conformity with the actual situations.

\section{Summary}

Based on smart growth, the paper has been studied the indicators of sustainable development of cities and put forward a suitable metric of evaluating the success of smart growth of a city. On the above, we use our metric to evaluate Zouping city and find it in conformity with the actual situations. Therefore, the metric we defined is reasonable. So, it can help us to judge the smart growth degree of a city. And it can provide reliable basis for the smart growth of the national policy. Of course, this metric should be applied according to local conditions, to determine the final results reliably.

\section{References}

[1] EPA, “This is Smart Growth.” 2016.

https://www.epa.gov/smartgrowth/smart-growth-publication Reference to a book:

[2] EPA, "Smart Growth: A Guide to Developing and Implementing Greenhouse Gas Reductions Programs.” 2011.

http://www.sustainablecitiesinstitute.org/Documents/SCI/Report_Guide/Guide_EPA_SmartGro wthGHGReduction_2011.pdf

[3] Qiang Ma and Xunchu Xu, "Smart Growth" Strategy and Urban Spatial Expansion in China, 2004.

[4] Zouping Bureau of Statistics. "The statistical bulletin of the economic and social development of Zouping ” 2016.

http://www.zouping.gov.cn/

[5] Yale University. “GLOBAL METRICS FOR THE ENVIRONMENT-2016 REPORT.” http://epi.yale.edu/sites/default/files/2016EPI_Full_Report_opt.pdf

[6] Yale University. "2014 ENVIRONMENTAL PERFORMANCE INDEX Full Report and Analysis.”

http://epi.yale.edu/sites/default/files/2014_epi_report_0.pdf

[7] Yale University. “2012 EPI : Environmental Performance Index and Pilot Trend Environmental Performance Index.”

http://epi.yale.edu/sites/default/files/2012_epi_report.pdf

[8] Yale University. “2010 ENVIRONMENTAL PERFORMANCE INDEX.”

http://epi.yale.edu/sites/default/files/2010_epi_report_2.pdf 